\title{
Análisis de la oferta turística del programa Pueblos mágicos Ecuador - 4 mundos
}

\author{
Analysis of the tourist offer of the Pueblos mágicos \\ Ecuador - 4 mundos program
}

\author{
Edison Rubén Molina Velásquez* \\ Pedro Andrés Villagrán Olivo \\ Franklin Raúl Guerrero Carvajal \\ Cristina Alejandra Villarreal Cando \\ Universidad Central del Ecuador, Ecuador
}

\section{RESUMEN}

En 2018 el Ministerio de Turismo del Ecuador (MINTUR) firma un convenio con la Secretaría de Turismo de México (SECTUR) para la implementación y desarrollo del Programa de Desarrollo de Localidades Pueblos Mágicos Ecuador - 4 Mundos. Luego de tres años de funcionamiento, y tomando en cuenta el impacto de la pandemia por COVID-19, se plantea como objetivo del presente trabajo analizar la oferta turística y la promoción para determinar el estado actual de la implementación del programa Pueblos Mágicos Ecuador. La investigación es de corte descriptivo y comparativo; de enfoque metodológico mixto; se complementa el estudio con el uso de sistemas de información geográfica SIG, para representar la distribución territorial y la concentración de los prestadores de servicios. Los principales resultados reflejan la tipología de atractivos turísticos, clasificación y concentración de prestadores de servicios, certificaciones y denominaciones, clasificación de áreas de conservación e información referente a la promoción turística por plataformas digitales. Pueblos Mágicos es un modelo de gestión que impulsa a la actividad turística, rescatando la identidad local y la revalorización del patrimonio. Depende directamente del compromiso de los actores vinculados al programa establecer estrategias promocionales.

Palabras clave: pueblos mágicos, promoción turística, modelo de gestión, política pública, Ecuador.

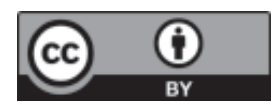




\begin{abstract}
In 2018, the Ministry of Tourism of Ecuador (MINTUR) signed an agreement with the Secretariat of Tourism of Mexico (SECTUR) for the implementation and development of the Pueblos Mágicos Ecuador - 4 Mundos Development Program. After three years of operation and taking into account the impact of the COVID-19 pandemic, the objective of this work is to analyze the tourist offer and promotion to determine the current status of the implementation of the Magic Towns Ecuador program. The research is descriptive and comparative; of mixed methodological approach; the study is complemented with the use of geographic information systems GIS, to represent the territorial distribution and the concentration of service providers. The main results reflect the typology of tourist attractions, classification and concentration of service providers, certifications and names, classification of conservation areas and information regarding tourism promotion through digital platforms. Pueblos Mágicos is a management model that promotes tourist activity, rescuing the local identity and the revaluation of heritage. It depends directly on the commitment of the actors linked to the program to establish promotional strategies.
\end{abstract}

Keywords: Magical towns, tourism promotion, management model, public policy, Ecuador.

\title{
Introducción
}

Pueblos Mágicos es un programa de política turística que se origina en 2001 bajo la dirección de la Secretaría de Turismo de México (SECTUR) con la colaboración de dependencias públicas, como gobiernos estatales y municipales, cuyo objetivo principal es fomentar el desarrollo sustentable de las localidades. El programa se orienta a la construcción de la oferta turística complementaria y diversificada implementando una estrategia de desarrollo turístico, en donde los atributos históricos, culturales y naturales, con características de singularidad y autenticidad posean valor mediante una marca exclusiva y de prestigio (SECTUR, 2017, p. 3). Con estas bases, en 2018 el Ministerio de Turismo del Ecuador (MINTUR), como parte de la cooperación turística, firma un convenio con SECTUR para la implementación y desarrollo de un programa, logrando con ello despertar el interés de varias localidades; las cuales vieron una oportunidad de desarrollo mediante la puesta en valor de sus atractivos y la generación de una oferta turística distintiva basada en la identidad local.

El presente estudio muestra la oferta del Programa de Desarrollo de Localidades Pueblos Mágicos Ecuador - 4 Mundos, tomando en cuenta el impacto de la COVID-19 ${ }^{1}$ en el turismo global, con un escenario devastador, reflejado en las decenas o miles de pérdidas en el sector turístico a nivel mundial, hoteles vacíos, restaurantes sin vida y operadores turísticos con escaso público a quien ofrecer sus servicios. En Ecuador, tanto el sector

1 Enfermedad originada por una cepa mutante de coronavirus, el SARS-CoV-2, virus que afecta de manera directa al sistema respiratorio, el primer caso se presenta en China en diciembre de 2019; en marzo de 2020, la Organización Mundial de la Salud (OMS) declara pandemia mundial (Maguiña et al., 2020). 
hotelero como el de restauración, siguen afrontando «pérdidas millonarias», llegando a situaciones insostenibles por las deudas asumidas, incluso desde antes de la crisis sanitaria (Seiscientos treinta hoteles del Ecuador permanecen cerrados, 2020, párr. 1). En este contexto, el programa Pueblos Mágicos Ecuador ha otorgado reconocimientos, apoyando de múltiples formas la reactivación económica de este sector afectado.

Luego de tres años, es necesario analizar la oferta turística y la promoción de los pueblos mágicos para describir el funcionamiento actual del programa y sus aportes al desarrollo de los territorios. Para ello, se recopila información acerca de cómo la normativa turística cubre estos programas en Ecuador, cuáles son las entidades a cargo y los beneficios para el desarrollo turístico. Asimismo, se exploran los ejes sobre los que se construye el programa en territorio mexicano, el concepto de un pueblo mágico y sus características, considerando que en este país ya se sigue estos procedimientos.

Cada pueblo mágico posee una singularidad única, y la forma de evaluar las potencialidades que posee un territorio es mediante el inventario de recursos turísticos de los pueblos mágicos proporcionado por el órgano rector del MINTUR; además de certificaciones o denominaciones de reconocimiento, las mismas que generan un valor agregado dentro del posicionamiento turístico de los destinos.

En esta investigación se examinan las plataformas sociales y la interacción promocional de los 21 pueblos mágicos registrados en Ecuador. Por consiguiente, se plantea como objetivo analizar la oferta turística y la promoción, para determinar el estado actual de la implementación del programa Pueblos Mágicos Ecuador.

\section{Programa Pueblos Mágicos México}

Cumpliendo con los objetivos del programa Pueblos Mágicos México se crea una marca turística distintiva, que en sus inicios contaba tan solo con 30 localidades; las primeras en recibir el nombramiento son Huasca de Ocampo en el estado de Hidalgo, Real de Catorce en San Luis Potosí y Mexcaltitán en Nayarit. Hasta octubre de 2020 se cuenta con 132 localidades con nombramiento, las mismas que se distribuyen de manera homogénea en el territorio (SECTUR, 2020, p. 13).

SECTUR (2017) define un pueblo mágico como:

Una localidad que a través del tiempo y ante la modernidad, ha conservado, valorado y defendido, su herencia histórica, cultural y natural; y la manifiesta en diversas expresiones a través de su patrimonio tangible e intangible. Un pueblo mágico es una localidad que tiene atributos únicos, simbólicos, historias auténticas, hechos trascendentes, cotidianidad, que significa una gran oportunidad para el aprovechamiento turístico atendiendo a las motivaciones y necesidades de los viajeros. (p. 4)

Para el año 2014, el Diario Oficial de la Federación (DOF) publica los lineamientos generales para la incorporación y permanencia en el Programa Pueblos Mágicos, en donde se detalla que aquellas localidades que deseen ser parte del programa deberán cumplir un modelo de gestión con los siguientes ejes importantes: 
- Sustentabilidad.

- Privilegiar la participación social.

- Procurar la inversión integral.

- Facilitar la corresponsabilidad entre los diferentes actores de las localidades.

- Impulsar la rendición de cuentas a través de indicadores.

\section{Programa Pueblos Mágicos Ecuador - 4 Mundos}

En Ecuador nace la iniciativa como resultado de un proceso de cooperación turística con México. Es así que en agosto de 2018 el ministro de Turismo del Ecuador, Enrique Ponce de León, firma el Programa de Cooperación en Materia Turística para la transferencia de metodologías y procesos del programa Pueblos Mágicos, que permitiría visibilizar y facilitar el análisis de la implementación y desarrollo de dicho programa en Ecuador. La acción se llevó a cabo mediante el intercambio de procedimientos, metodologías y buenas prácticas de desarrollo turístico del exitoso programa (Alcívar, 2018).

En octubre del mismo año, representantes de la SECTUR, realizaron un viaje a Ecuador y visitaron diferentes lugares con potencial turístico para convertirse en pueblos mágicos. Lugares como Baños y Patate, ubicados en la provincia de Tungurahua, Zaruma en la provincia de El Oro y Cotacachi de la provincia de Imbabura, fueron los elegidos para conocer acerca de los servicios, atractivos e información turística que ofertan; elementos que fueron importantes para la consolidación de este programa en el país. En esta visita los actores locales de cada cantón ${ }^{2}$ obtuvieron una retroalimentación con la delegación mexicana acerca de su experiencia en la ejecución del programa Pueblos Mágicos México. Como resultado se logró el fortalecimiento de relaciones entre ambos ministerios y también la consolidación de actividades de cooperación para el desarrollo turístico en el Ecuador.

El siguiente mes, en noviembre de 2018, se ejecutó un pilotaje en cuatro cantones: Alausí, Zaruma, Cotacachi y Patate, esto, en el marco de intercambio de experiencias, metodologías y aplicación del programa Pueblos Mágicos. Con ayuda de una delegación técnica de la SECTUR, un equipo multidisciplinario del MINTUR y los representantes de los Gobiernos Autónomos Descentralizados (GAD), se brindó apoyo, soporte y aclaración de dudas a los actores de las localidades sobre el procedimiento para convertirse en pueblos mágicos de Ecuador. Como resultado de este piloto se recibieron varias recomendaciones de la delegación mexicana que pusieron énfasis en el desarrollo de productos turísticos para generar la llegada de turistas dispuestos a pernoctar en los diferentes destinos.

El cantón es una circunscripción territorial conformada por un conjunto de parroquias rurales y una cabecera cantonal con sus parroquias urbanas según el artículo 20 del Código Orgánico de Organización Territorial, Autonomía y Descentralización - COOTAD (Córdoba y Vivanco, 2021). 
[Pueblos Mágicos Ecuador se orienta a] la identificación y puesta en valor de las poblaciones que cuentan con potencial turístico, es decir que cumplen las condiciones necesarias básicas para el desarrollo de esta actividad, por tal razón se convierte en un programa que fomenta la competitividad y facilita la implementación de acciones de fortalecimiento en el ámbito turístico, considerando que el cumplimiento de estas condiciones básicas afianza las iniciativas de inversión pública y privada. (MINTUR, 2020a)

En 2019 comienza la convocatoria dentro de Ecuador y el programa transmite una concepción de desarrollo y fomento de progreso en sus localidades. El objetivo es el siguiente:

Promover el desarrollo turístico de poblaciones que cuentan con atributos culturales y naturales singulares que cumplan con las condiciones básicas necesarias para el desarrollo de la actividad turística, mediante un programa de fortalecimiento que facilite la implementación de un modelo de desarrollo turístico local. (MINTUR, 2020b)

En la guía de lineamientos para la incorporación y permanencia en el programa de desarrollo turístico de localidades Pueblos Mágicos Ecuador - 4 Mundos se consideran 15 requisitos, 5 de registros: unidad administrativa, catastro de prestadores de servicios turísticos, inventarios de atractivos turísticos, georreferenciación, distribución y herramienta de planificación municipal; y 10 de incorporación: comité ciudadano, aprobación consejo municipal, respaldo GAD provincial, asignación presupuestaria, programa bianual, ordenanza municipales turísticas, atractivo turístico excepcional, servicios de salud y seguridad, inversión pública y privada en la localidad, compromiso de fortalecer la cadena productiva local. En junio de 2019, el primer pueblo en cumplir los requisitos fue el cantón Patate, conocido como el «Valle de la Eterna Primavera» (MINTUR, 2020b). Hasta la fecha se tiene un listado de 21 pueblos mágicos en el territorio ecuatoriano (Pinchevsky, 2021).

El proceso para la implementación de un pueblo mágico en el territorio ecuatoriano requiere de un calendario anual de incorporación que va desde la convocatoria nacional, recepción, validación de documentos, análisis de potencialidad, periodo de subsanación, expediente técnico, evaluación del comité hasta la declaración de un nuevo pueblo mágico. Es decir, la propuesta es vinculante para los 221 cantones y 1140 parroquias rurales ${ }^{3}$ (Molina, 2021).

3 Las parroquias rurales constituyen circunscripciones territoriales integradas a un cantón a través de ordenanza expedida por el respectivo concejo municipal o metropolitano (Código Orgánico de Organización Territorial, Autonomía y Descentralización [COOTAD], 2010). 


\section{Oferta turística nacional de los pueblos mágicos}

La oferta turística en Ecuador es variada debido a la versatilidad del territorio y su riqueza tanto natural como cultural. Si se tiene en cuenta que el espacio geográfico turístico se construye con elementos físicos como relieve, clima, entre otros, abarcando hasta las complejas interacciones sociales, se puede decir que la implementación de un modelo de gestión es una estrategia aplicable puesto que el enfoque nacional se orienta hacia el desarrollo sostenible. En ese sentido, cada una de las localidades dentro del programa, pueden percibir que estas múltiples vinculaciones permiten la conformación de un espacio turístico llamativo para los visitantes. Este se compone de tres dimensiones: (1) configuración territorial, (2) jerarquía de los atractivos turísticos y (3) la disposición de la prestación de servicios básicos y turísticos; sacando a relucir sus características únicas.

En cuanto a la configuración territorial, los factores geográficos son fundamentales para el desarrollo de las actividades turísticas, ya que a partir de ello se producen flujos turísticos (Pazos, 2001). Los factores geográficos, como son paisaje turístico, sitio turístico, condiciones climatológicas, masas de agua, biodiversidad, cultura popular, herencia histórica, arte, religión y deportes pueden estar activos en los territorios (Molina et al., 2021). Por ejemplo, las diferentes modalidades turísticas practicadas en los 21 pueblos mágicos, yendo desde el ecoturismo, hasta una integración cultural profunda con el turismo vivencial.

La jerarquía de los atractivos turísticos permite establecer las condiciones para el desarrollo de atractivos turísticos. Según el MINTUR (2017, p. 15), los atractivos turísticos en el Ecuador se pueden clasificar en dos categorías: (1) sitios naturales (montañas, planicies, desiertos, ambientes lacustres, ríos, bosques, aguas subterráneas, fenómenos espeleológicos, fenómenos geológicos, costas o Litorales, ambientes marinos y tierras insulares) y (2) manifestaciones culturales (arquitectura, folklore, realizaciones técnicas y científicas y acontecimientos programados); cada uno con sus respectivos tipos y subtipos.

Para satisfacer la demanda se debe contar con una planta turística diversa con servicios suficientes para cubrir las necesidades del visitante. En Ecuador se maneja un catastro de actividades turísticas que se basa en la Ley Orgánica de Turismo (2002), Capítulo II: Actividades turísticas y quienes las ejercen, que involucra a tópicos como alojamiento, alimentos y bebidas, intermediación, operación e intermediación, parques y atracciones estables, transporte turístico y la posterior adhesión de los Centros de Turismo Comunitario, servicios que permiten elevar el nivel de la experiencia turística.

La oferta turística debe tener preparada las prestaciones funcionales y simbólicas para la promoción en plataformas digitales como Instagram, Facebook, YouTube y otras acordes a la tecnología actual. Lo que se suma a las páginas web actualizadas constantemente con contenido ofertado más personalizado y dinámico (Pineda et al., 2019). 


\section{Creación y evolución de Pueblos Mágicos Ecuador}

En la Figura 1 se detalla la evolución del proyecto Pueblos Mágicos Ecuador, dando inicio con el pilotaje en el año 2018, alcanzando para el 2019 la primera declaratoria del país. A raíz de esta primera declaratoria se nota el interés generado por nuevas localidades ubicadas en la serranía ecuatoriana y posteriormente ampliándose a todo el país, incluyendo la región insular de Galápagos, alcanzando un total de 21 registros en 2021.

\section{Figura 1}

Línea de tiempo de los pueblos mágicos

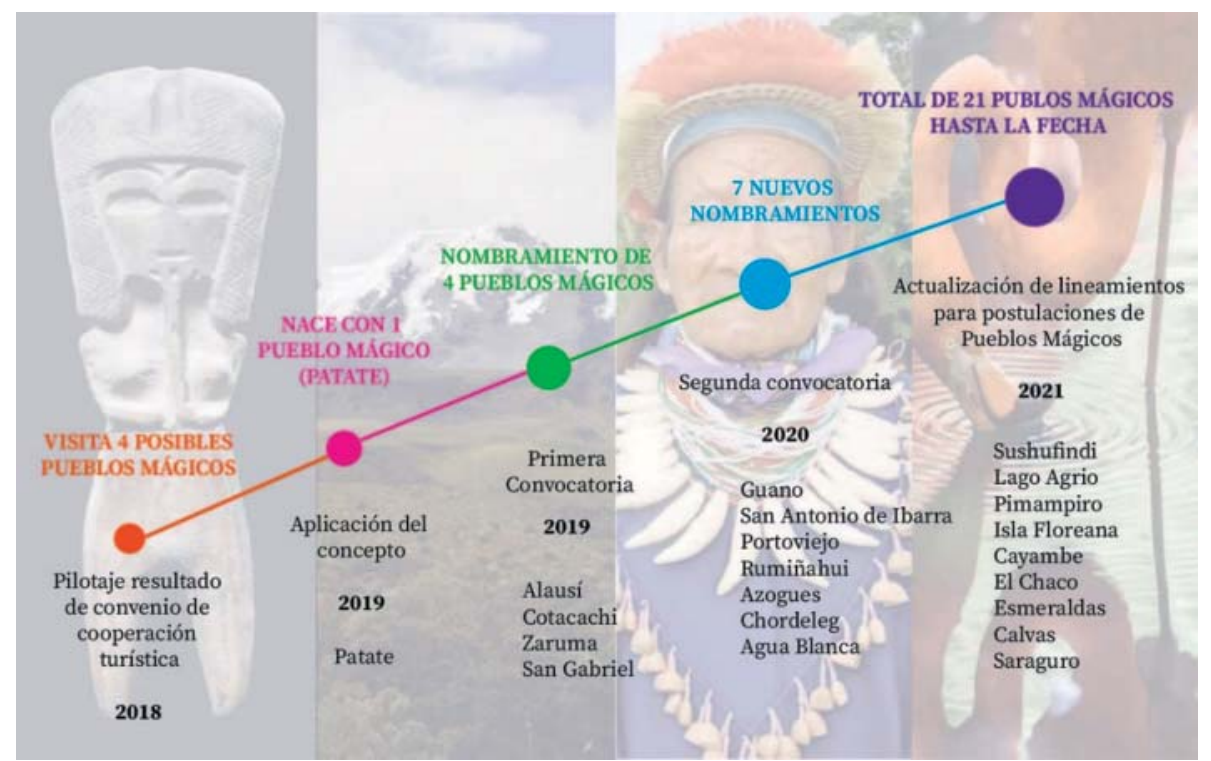

\section{Certificaciones y denominaciones}

Dentro del campo turístico existen varias estrategias comerciales que ayudan a elevar el nivel de percepción que se tiene de los diferentes destinos turísticos, ayudando con esto a brindar una experiencia única al turista. La certificación se compone de características asociadas a un producto o servicio, brindando una garantía por escrito de la calidad que poseen independientemente del sector económico al que pertenezcan, y que lo convierte así en una ventaja comercial indiscutible. Por otro lado, las denominaciones son aquellas cuya motivación se basa en los diferentes ámbitos, ya sean sociales, culturales o naturales; convirtiéndose en gestores de políticas de desarrollo sostenible; esto constituye un elemento estructural para los diferentes destinos turísticos (Sánchez, 2018).

En la Tabla 1 se presenta la descripción de la certificación Safe Travel y de las 10 denominaciones identificadas para el estudio (ver información completa en el Anexo 1). 
Tabla 1

Certificación y denominaciones

\begin{tabular}{|c|c|c|}
\hline & Nombre & Descripción \\
\hline 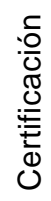 & Safe Travel & $\begin{array}{l}\text { Sello de calidad diseñado por el Consejo } \\
\text { Mundial de Viajes y Turismo (World Travel and } \\
\text { Tourism Conuncil, 2021). }\end{array}$ \\
\hline \multirow{10}{*}{ 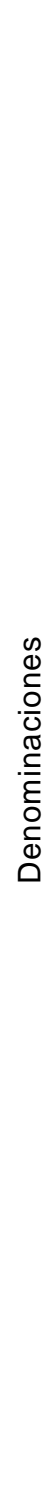 } & Ciudades Creativas & $\begin{array}{l}\text { Dadas a las artesanías o artes populares, artes } \\
\text { digitales, cine, diseño, gastronomía, literatura y } \\
\text { música (Barchello, 2020). }\end{array}$ \\
\hline & $\begin{array}{l}\text { Patrimonio Cultural } \\
\text { Inmaterial del Ecuador }\end{array}$ & $\begin{array}{l}\text { Promueve el sentimiento de identidad motivando } \\
\text { con esto la valoración de lo propio (Guerrero et } \\
\text { al., 2020). }\end{array}$ \\
\hline & $\begin{array}{l}\text { Patrimonio de la } \\
\text { Humanidad }\end{array}$ & $\begin{array}{l}\text { Establece la protección de ciertos lugares de la } \\
\text { tierra que tengan un «valor excepcional universal» } \\
\text { (Ministerio de Cultura y Patrimonio, 2021; Parque } \\
\text { Nacional Galápagos, 2018). }\end{array}$ \\
\hline & Denominación de Origen & $\begin{array}{l}\text { Identifican una región o un lugar determinado y } \\
\text { coexisten con factores naturales y humanos } \\
\text { (Servicio Nacional de Derechos Intelectuales, } \\
\text { 2021). }\end{array}$ \\
\hline & Áreas Protegidas & $\begin{array}{l}\text { Destinados a garantizar la conservación de la } \\
\text { biodiversidad y el mantenimiento de las } \\
\text { funciones ecológicas (Sistema Nacional de } \\
\text { Áreas Protegidas del Ecuador, 2021). }\end{array}$ \\
\hline & Reserva de la biosfera & $\begin{array}{l}\text { Gestiona una apropiada sustentabilidad y } \\
\text { convivencia entre los seres humanos y la } \\
\text { naturaleza (Sistema Nacional de Áreas de } \\
\text { Conservación Costa Rica, 2021). }\end{array}$ \\
\hline & Santuario de Ballenas & $\begin{array}{l}\text { Vela por la conservación adecuada de los } \\
\text { cetáceos (International Whaling Commission } \\
\text { 2021). }\end{array}$ \\
\hline & Sitios RAMSAR & $\begin{array}{l}\text { Humedales destacados por su alto valor } \\
\text { biológico mundial (Ministerio del Ambiente de } \\
\text { Ecuador, 2019). }\end{array}$ \\
\hline & $\begin{array}{l}\text { Áreas importantes para } \\
\text { las aves y la biodiversidad } \\
\text { (IBA) }\end{array}$ & $\begin{array}{l}\text { Sitios identificados para la protección y custodia } \\
\text { de poblaciones de aves (BirdLife International } \\
\text { 2021). }\end{array}$ \\
\hline & Hotspots & $\begin{array}{l}\text { Ecorregiones críticas de gran diversidad } \\
\text { (Conservation International, 2020). }\end{array}$ \\
\hline
\end{tabular}




\section{Metodología}

La investigación tiene un enfoque mixto, tomando en cuenta las particularidades de los análisis cualitativo y cuantitativo. El enfoque cualitativo corresponde a la profusa revisión bibliográfica del programa Pueblo Mágicos Ecuador y otros documentos oficiales sobre la oferta turística, tomando en consideración los atractivos turísticos, los prestadores de servicios, las certificaciones y denominaciones, así como la promoción turística. El cuantitativo corresponde a la digitalización de la información de bases de datos oficiales del MINTUR y la adaptación a una tabla de atributos madre para la construcción de tres productos cartográficos, diseñados por la carga y edición de datos vectoriales aplicando los sistemas de información geográfica SIG, utilizando el programa ArcGis 10.3. Además, es de carácter observacional y de corte descriptivo y comparativo.

El universo lo conforman las 21 localidades del país, en un periodo de tiempo que va desde noviembre de 2020 hasta abril de 2021.

Para el análisis de los datos se cuenta con una estructura de ingreso de información en matrices de Excel que aportan al reconocimiento de la oferta turística clasificada en atractivos turísticos naturales, manifestaciones culturales y servicios turísticos reconocidos en la Ley Orgánica de Turismo del Ecuador (2002). Por consiguiente, se presentan 6 tablas de ingresos de datos: la primera tabla de atractivos turísticos cuenta con los parámetros de tipología (Aatractivo natural y manifestaciones culturales) y localización geográfica (rural, urbano). La segunda tabla presenta la clasificación y concentración de prestadores de servicios (alimentos y bebidas, alojamiento, operación e intermediación, intermediación, transporte turístico, parques de atracciones estables y centros de turismo comunitario). La tercera tabla está dedicada al ingreso de datos acerca de las certificaciones y denominaciones (Safe Travel, denominación de origen, patrimonio cultural inmaterial del Ecuador, ciudades creativas y patrimonio de la humanidad). La cuarta tabla que se utiliza para clasificar a las áreas de conservación (áreas protegidas, santuario de ballenas, reserva de la biosfera, sitios Ramsar, sitios IBA y hotspot) dentro de la localidad de pueblos mágicos. Por último, la quinta y sexta tabla aportan al registro de información sobre promoción turística por medio de plataformas digitales (Facebook, Instagram, YouTube y sitios web).

\section{Resultados}

\section{Atractivos turísticos}

En la Figura 2, se observa la distribución de los 21 Pueblos Mágicos:13 de 21 localidades se ubican en provincias de la sierra nacional, 3 de 21 localidades se ubican en las provincias de la Amazonía norte, 4 de 21 localidades se encuentran dispersas en las provincias de la zona litoral del país y apenas un pueblo mágico se registra en el archipiélago de Galápagos; 15 de 24 provincias del Ecuador poseen al menos una localidad declarada como pueblo mágico, siendo la provincia de Imbabura donde se encuentra la mayor concentración con esta denominación. 


\section{Figura 2}

Mapa de ubicación del programa Pueblos Mágicos Ecuador

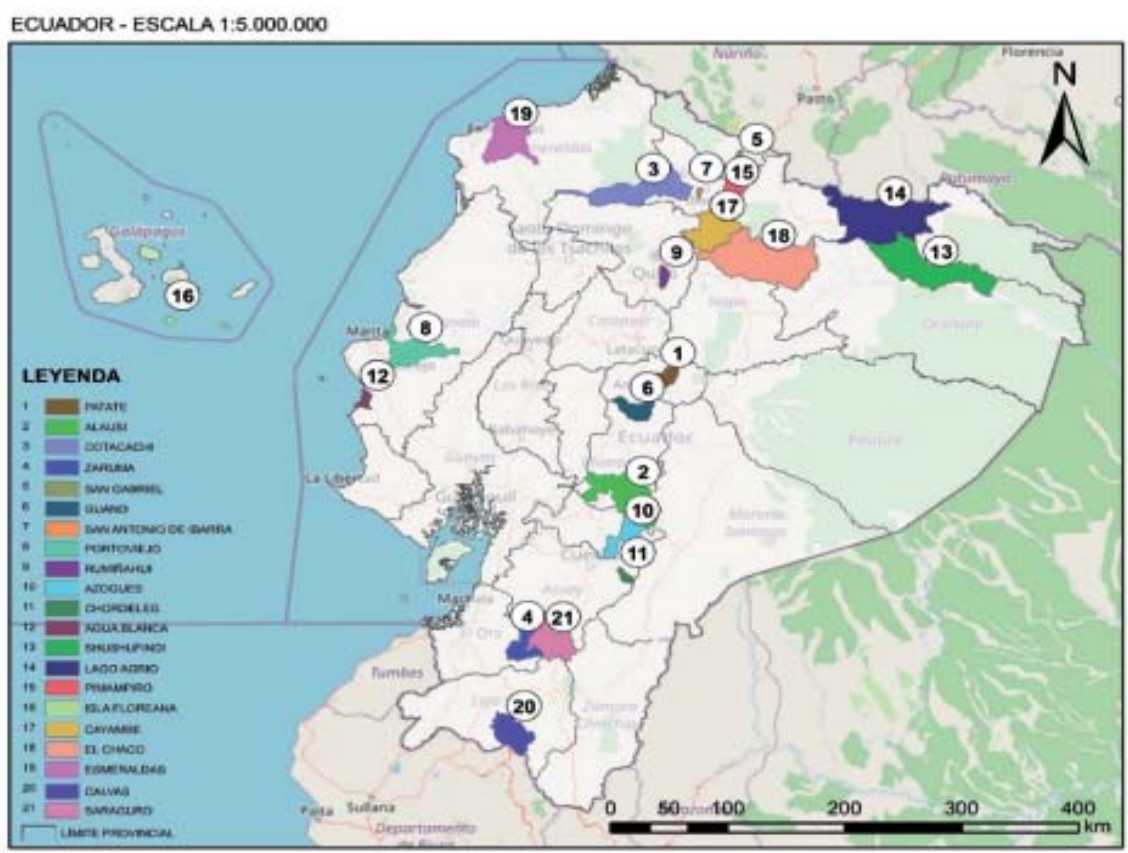

En la Figura 3 se aprecia que $86 \%$ de los pueblos mágicos fueron declarados bajo la escala geográfica cantonal; mientras que 14\% bajo la escala geográfica parroquial, tomando en cuenta la extensión territorial.

\section{Figura 3}

Mapa Pueblos Mágicos Ecuador, urbano/rural

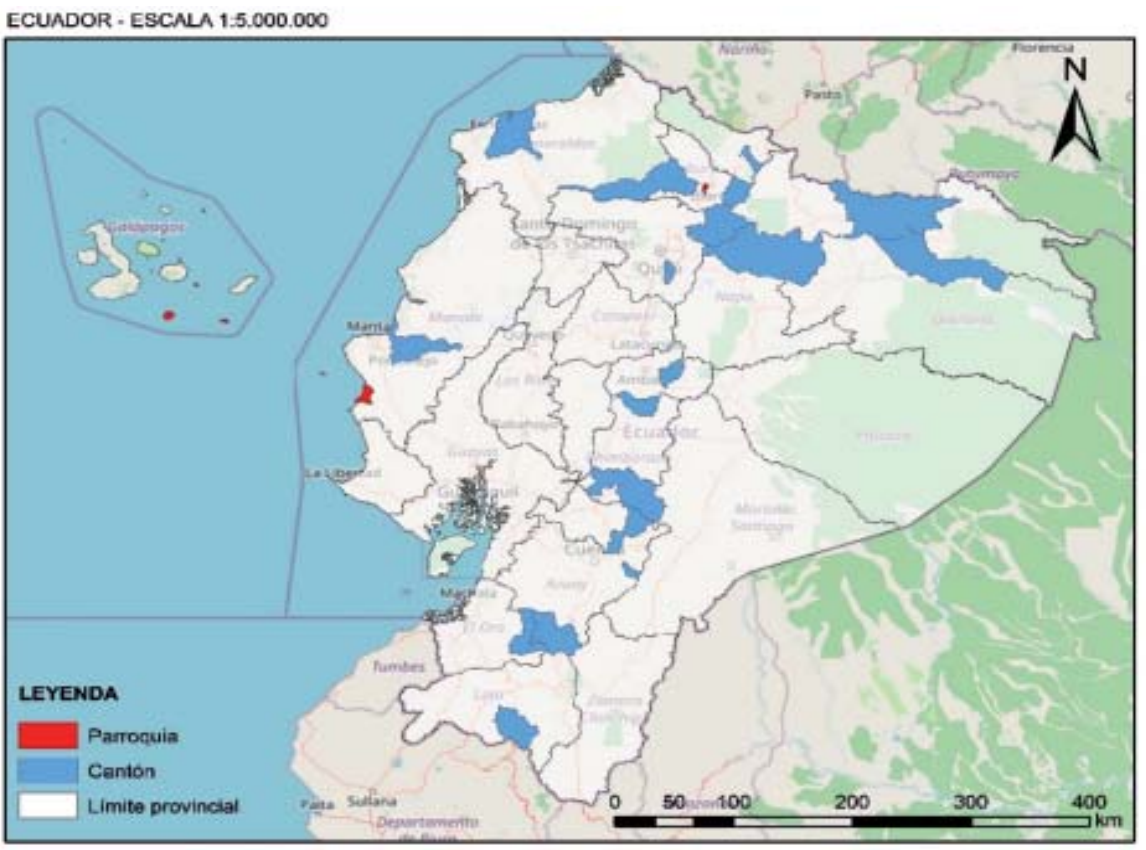


Uno de los requisitos previos para ser considerado dentro del programa Pueblos Mágicos Ecuador, es contar con el inventario de atractivos turísticos. Actualmente existe un registro de 75 atractivos turísticos (naturales y culturales) registrados en 12 localidades, el restante no dispone de fichas de atractivos (ver Anexo 2).

Cabe mencionar que la Asociación de Municipalidades Ecuatorianas (2016) publica la Resolución N. ${ }^{001-}$ CNC- 2016, sección II, artículo 13, numeral 3 donde se establece lo siguiente:

En el marco del desarrollo de actividades turísticas corresponde a los gobiernos autónomos descentralizados municipales y metropolitanos: Elaborar y actualizar el inventario de atractivos turísticos de su circunscripción, de conformidad con la normativa expedida por la Autoridad Nacional de Turismo.

A medida que los GAD remitan al MINTUR las fichas de atractivos de sus jurisdicciones, la base de datos de atractivos se actualiza.

En la Tabla 2 se observa que 77\% de los atractivos son manifestaciones culturales, localizadas en su mayoría, en zonas urbanas y 33\% son atractivos naturales, localizados en su mayoría, en zonas rurales. De los 12 pueblos mágicos que poseen registro de inventario de los atractivos turísticos, 7 de cada 12 poseen atractivos naturales y 11 de cada 12 poseen manifestaciones culturales. El pueblo mágico de Rumiñahui es el que registra la mayor concentración de atractivos turísticos con un total de 26, seguido de Zaruma con 15.

El resto de localidades poseen al menos dos sitios de relevancia, a excepción de Alausí, Guano y Cayambe que registran solo uno. El 66\% de los atractivos turísticos se encuentran localizados en las zonas urbanas. Los pueblos mágicos declarados entre los años 2020 y 2021 presentan un registro de 0 atractivos, debido a la actualización que están realizando los GAD; sin embargo, para la declaratoria de los pueblos mágicos, las 21 localidades poseen un atractivo diferenciador tal como dicta el programa. 
Tabla 2

Atractivos turísticos del programa Pueblos Mágicos Ecuador

\begin{tabular}{|c|c|c|c|c|c|c|c|}
\hline & \multirow{2}{*}{ Pueblo mágico } & \multirow{2}{*}{ Provincia } & \multicolumn{2}{|c|}{ Atractivo natural } & \multicolumn{2}{|c|}{ Manifestaciones culturales } & \multirow{2}{*}{ Total } \\
\hline & & & Urbano & Rural & Urbano & Rural & \\
\hline 1 & Patate & Tungurahua & 1 & 0 & 1 & 0 & 2 \\
\hline 2 & Alausí & Chimborazo & 0 & 0 & 0 & 1 & 1 \\
\hline 3 & Cotacachi & Imbabura & 0 & 1 & 2 & 0 & 3 \\
\hline 4 & Zaruma & El Oro & 0 & 0 & 6 & 9 & 15 \\
\hline 5 & San Gabriel & Carchi & 2 & 0 & 0 & 0 & 2 \\
\hline 6 & Guano & Chimborazo & 0 & 0 & 1 & 0 & 1 \\
\hline 7 & San Antonio de Ibarra & Imbabura & 0 & 0 & 3 & 2 & 5 \\
\hline 8 & Portoviejo & Manabí & 0 & 4 & 5 & 0 & 9 \\
\hline 9 & Rumiñahui & Pichincha & 1 & 7 & 18 & 0 & 26 \\
\hline 10 & Azogues & Cañar & 0 & 0 & 0 & 0 & 0 \\
\hline 11 & Chordeleg & Azuay & 0 & 0 & 2 & 0 & 2 \\
\hline 12 & Agua Blanca & Manabí & 0 & 0 & 0 & 0 & 0 \\
\hline 13 & Shushufindi & Sucumbíos & 0 & 0 & 0 & 0 & 0 \\
\hline 14 & Lago Agrio & Sucumbíos & 0 & 0 & 0 & 0 & 0 \\
\hline 15 & Pimampiro & Imbabura & 0 & 0 & 0 & 0 & 0 \\
\hline 16 & Isla Floreana & Galápagos & 0 & 0 & 0 & 0 & 0 \\
\hline 17 & Cayambe & Pichincha & 0 & 0 & 0 & 1 & 1 \\
\hline 18 & El Chaco & Napo & 0 & 0 & 0 & 0 & 0 \\
\hline 19 & Esmeraldas & Esmeraldas & 1 & 0 & 7 & 0 & 8 \\
\hline 20 & Calvas & Loja & 0 & 0 & 0 & 0 & 0 \\
\hline 21 & Saraguro & Loja & 0 & 0 & 0 & 0 & 0 \\
\hline & Total & & 5 & 12 & 45 & 13 & 75 \\
\hline
\end{tabular}

Nota. Información del Inventario de atractivos turísticos del Ministerio de Turismo, 2021.

\section{Servicios turísticos}

Basados en el consolidado turístico de los prestadores de servicios proporcionado por el MINTUR, los pueblos mágicos concentran el 7.3\% de la base general total, siendo 1416 establecimientos. Como se puede apreciar en la Figura 4, en las localidades de Portoviejo y Rumiñahui existe una gran concentración de prestadores de servicios con un máximo de 325 establecimientos, seguido de Esmeraldas, Lago Agrio, Chordeleg y Cayambe, puesto que poseen más de 100 establecimientos registrados con un máximo de 143; mientras que, las localidades restantes tienen un registro bajo (al menos tres) de prestadores de servicios. 


\section{Figura 4}

Mapa de concentración de prestadores de servicios

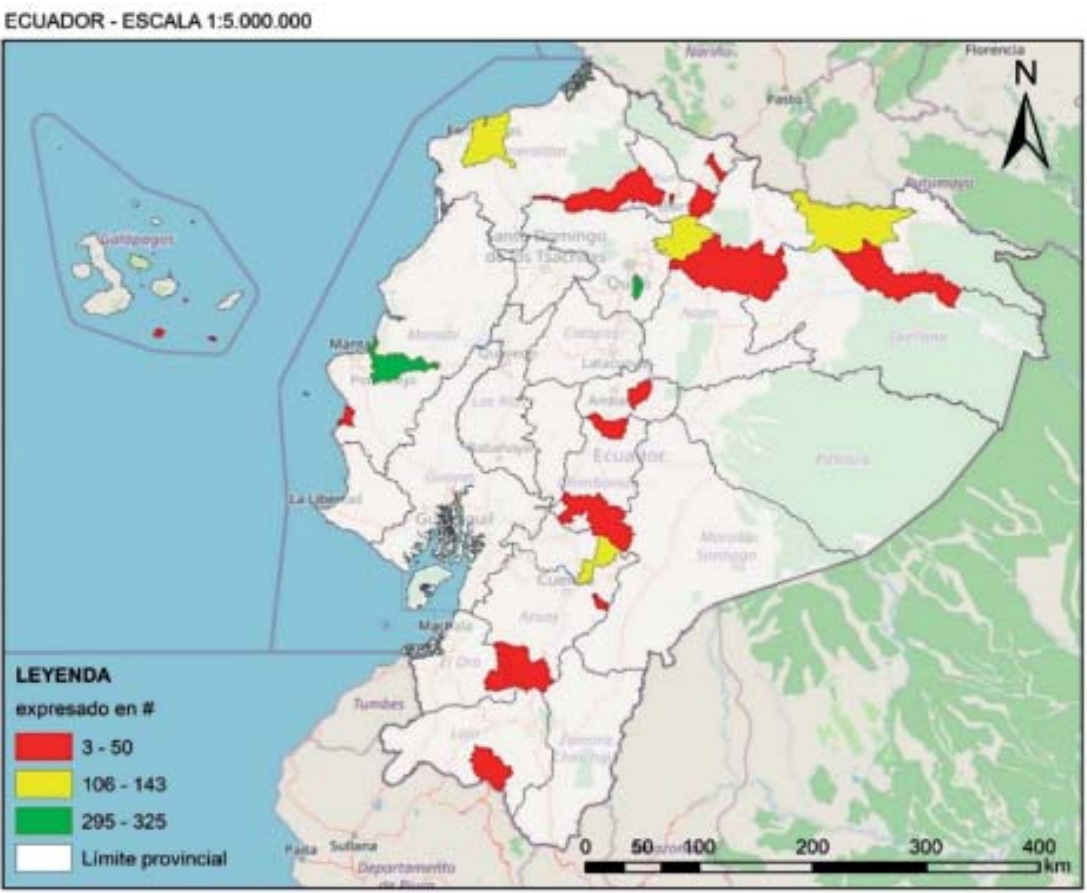

En Ecuador los servicios turísticos son reconocidos como actividades turísticas según la Ley Orgánica de Turismo (2002). En la Tabla 3, el 62\% de los prestadores de servicios se dedica a la actividad de alimentos y bebidas, seguido de alojamiento con el 24\%, operación e intermediación 7\%, intermediación 3\%, transporte turístico y parques de atracciones estables el $2 \%$ y centros de turismo comunitario al poseer 4 registros en distintas localidades reflejan menos del $1 \%$ dentro de la muestra total.

Las 21 localidades declaradas cuentan mayoritariamente con el servicio de alimentos y bebidas, 18 localidades cuentan con alojamientos, 4 con centros de turismo comunitario, 9 con intermediación, 16 con operación e intermediación turística, 10 con parques de atracciones estables y 9 localidades con transporte turístico. Solamente el pueblo mágico de Portoviejo cuenta con prestadores de servicios en todas las actividades mencionadas; no obstante, es el segundo con mayor número de registro de establecimientos; por el contrario, Chordeleg únicamente registra prestadores de servicio en la actividad de alimentos y bebidas. Los poblados de San Gabriel, San Antonio de Ibarra, Chordeleg, Agua Blanca y Pimampiro no superan los 10 registros de prestadores de servicio. 
Tabla 3

Prestadores de servicios registrados

\begin{tabular}{|c|c|c|c|c|c|c|c|c|c|}
\hline & Pueblo mágico & $\begin{array}{l}\text { Alimentos y } \\
\text { bebidas }\end{array}$ & Alojamiento & $\begin{array}{l}\text { Centros de } \\
\text { turismo } \\
\text { comunitario }\end{array}$ & Intermediación & $\begin{array}{c}\text { Operación e } \\
\text { intermediación } \\
\text { turística }\end{array}$ & $\begin{array}{l}\text { Parques de } \\
\text { atracciones } \\
\text { estables }\end{array}$ & $\begin{array}{l}\text { Transporte } \\
\text { turístico }\end{array}$ & Total \\
\hline 1 & Patate & 13 & 4 & 0 & 1 & 2 & 0 & 0 & 20 \\
\hline 2 & Alausí & 12 & 13 & 1 & 0 & 1 & 2 & 0 & 29 \\
\hline 3 & Cotacachi & 24 & 20 & 0 & 0 & 3 & 0 & 3 & 50 \\
\hline 4 & Zaruma & 34 & 8 & 0 & 1 & 1 & 2 & 0 & 46 \\
\hline 5 & San Gabriel & 2 & 0 & 0 & 0 & 1 & 0 & 1 & 4 \\
\hline 6 & Guano & 9 & 7 & 0 & 0 & 0 & 0 & 0 & 16 \\
\hline 7 & $\begin{array}{l}\text { San Antonio } \\
\text { de Ibarra }\end{array}$ & 3 & 1 & 0 & 0 & 0 & 0 & 0 & 4 \\
\hline 8 & Portoviejo & 196 & 50 & 1 & 14 & 27 & 4 & 3 & 295 \\
\hline 9 & Rumiñahui & 247 & 35 & 0 & 3 & 33 & 2 & 5 & 325 \\
\hline 10 & Azogues & 62 & 9 & 0 & 12 & 14 & 1 & 8 & 106 \\
\hline 11 & Chordeleg & 7 & 0 & 0 & 0 & 0 & 0 & 0 & 7 \\
\hline 12 & Agua Blanca & 3 & 4 & 0 & 0 & 2 & 0 & 0 & 9 \\
\hline 13 & Shushufindi & 12 & 29 & 1 & 1 & 1 & 5 & 0 & 49 \\
\hline 14 & Lago Agrio & 47 & 61 & 0 & 2 & 4 & 4 & 4 & 122 \\
\hline 15 & Pimampiro & 2 & 0 & 0 & 0 & 0 & 1 & 0 & 3 \\
\hline 16 & Isla Floreana & 6 & 10 & 0 & 0 & 1 & 0 & 0 & 17 \\
\hline 17 & Cayambe & 101 & 27 & 0 & 5 & 4 & 4 & 2 & 143 \\
\hline 18 & El Chaco & 7 & 11 & 1 & 0 & 1 & 0 & 0 & 20 \\
\hline 19 & Esmeraldas & 67 & 37 & 0 & 3 & 6 & 4 & 1 & 118 \\
\hline 20 & Calvas & 7 & 10 & 0 & 0 & 0 & 0 & 0 & 17 \\
\hline \multirow[t]{2}{*}{21} & Saraguro & 8 & 5 & 0 & 0 & 2 & 0 & 1 & 16 \\
\hline & Total & 869 & 341 & 4 & 42 & 103 & 29 & 28 & 1416 \\
\hline
\end{tabular}

Nota. Consolidado de prestadores de servicios turísticos del Ministerio de Turismo (2021).

\section{Certificaciones y denominaciones}

En la Tabla 4 se evidencia que 8 de cada 21 pueblos poseen el certificado Safe Travel, 12 de cada 21 cuentan con denominación de origen dentro de su territorio, 10 de cada 21 contienen dentro de su territorio a una ciudad patrimonial catalogada como Patrimonio Inmaterial del Ecuador, 2 de cada 21 ha sido denominada Ciudad Creativa y 1 de cada 21 se acredita la denominación de Patrimonio de la Humanidad por formar parte de uno. Por otro lado, basados en el número de certificados y denominaciones, el $10 \%$ de los pueblos no los poseen, $48 \%$ tienen uno, 23\% cuentan con dos y el 19\% cuentan con tres certificados y/o denominaciones. 
Tabla 4

Certificación y denominaciones

\begin{tabular}{|c|c|c|c|c|c|}
\hline Pueblo Mágico & Safe Travel & $\begin{array}{l}\text { Denominación } \\
\text { de origen }\end{array}$ & $\begin{array}{l}\text { Patrimonio Cultural } \\
\text { Inmaterial del Ecuador }\end{array}$ & $\begin{array}{l}\text { Ciudades } \\
\text { Creativas }\end{array}$ & $\begin{array}{l}\text { Patrimonio de } \\
\text { la Humanidad }\end{array}$ \\
\hline Patate & $x$ & & & & \\
\hline Alausí & & $x$ & $x$ & & \\
\hline Cotacachi & $x$ & & & & \\
\hline Zaruma & $x$ & $x$ & $x$ & & \\
\hline San Gabriel & & & $x$ & & \\
\hline \multicolumn{6}{|l|}{ Guano } \\
\hline San Antonio de Ibarra & & $x$ & & & \\
\hline Portoviejo & $x$ & & $x$ & $x$ & \\
\hline Rumiñahui & $x$ & & $x$ & & \\
\hline Azogues & $x$ & & $x$ & & \\
\hline Chordeleg & & & & $x$ & \\
\hline Agua Blanca & & $x$ & & & \\
\hline Shushufindi & & $x$ & & & \\
\hline Lago Agrio & & $x$ & & & \\
\hline \multicolumn{6}{|l|}{ Pimampiro } \\
\hline Isla Floreana & $x$ & $x$ & & & $x$ \\
\hline Cayambe & $x$ & & $x$ & & \\
\hline El Chaco & & $x$ & & & \\
\hline Esmeraldas & & $x$ & $x$ & & \\
\hline Calvas & & $x$ & & & \\
\hline Saraguro & & $x$ & $x$ & & \\
\hline
\end{tabular}

En la Tabla 5, 14 de cada 21 pueblos contienen dentro de sus límites parte representativa de un área protegida registrada en el Sistema Nacional de Áreas Protegidas del Ecuador, 1 de cada 21 pueblos poseen dentro de su territorio un área de conservación especial denominado como Santuario de ballenas, 10 de cada 21 pueblos contienen dentro de su territorio áreas consideradas como Reservas de la biosfera, 1 de cada 21 se encuentra cerca de un Sitio Ramsar, 17 de cada 21 se encuentran cerca de un Área importante para la conservación de las aves (IBA) y 18 de cada 21 se encuentran dentro de un hotspot. 
Tabla 5

Áreas de conservación cercanas

\begin{tabular}{|c|c|c|c|c|c|c|}
\hline Pueblo mágico & $\begin{array}{c}\text { Área } \\
\text { protegida }\end{array}$ & $\begin{array}{c}\text { Santuario de } \\
\text { ballenas }\end{array}$ & $\begin{array}{c}\text { Reserva de la } \\
\text { biosfera }\end{array}$ & $\begin{array}{c}\text { Sitios } \\
\text { Ramsar }\end{array}$ & $\begin{array}{l}\text { Sitios } \\
\text { IBA }\end{array}$ & Hotspots \\
\hline Patate & $\mathrm{O}$ & & & & 0 & $x$ \\
\hline Alausí & $\mathrm{O}$ & & & & $\mathrm{O}$ & $x$ \\
\hline Cotacachi & O & & $\mathrm{O}$ & & O & $x$ \\
\hline Zaruma & & & $\mathrm{O}$ & & $\mathrm{O}$ & $x$ \\
\hline San Gabriel & $\mathrm{O}$ & & & & $\mathrm{O}$ & $x$ \\
\hline Guano & $\mathrm{O}$ & & & & & $x$ \\
\hline San Antonio de Ibarra & & & & & & $x$ \\
\hline Portoviejo & & & & & & $x$ \\
\hline Rumiñahui & & & $\mathrm{O}$ & & & $x$ \\
\hline Azogues & $\mathrm{O}$ & & $\mathrm{O}$ & & $\mathrm{O}$ & $x$ \\
\hline Chordeleg & $\mathrm{O}$ & & $\mathrm{O}$ & & $\mathrm{O}$ & $x$ \\
\hline Agua Blanca & $x$ & & & & $\mathrm{O}$ & $x$ \\
\hline Shushufindi & $\mathrm{O}$ & & $\mathrm{O}$ & $\mathrm{O}$ & $\mathrm{O}$ & \\
\hline Lago Agrio & $\mathrm{O}$ & & & & $\mathrm{O}$ & \\
\hline Pimampiro & & & & & $\mathrm{O}$ & $x$ \\
\hline Isla Floreana & $x$ & $x$ & $x$ & & $\mathrm{O}$ & $x$ \\
\hline Cayambe & $\mathrm{O}$ & & & & $\mathrm{O}$ & $x$ \\
\hline El Chaco & $\mathrm{O}$ & & $\mathrm{O}$ & & $\mathrm{O}$ & \\
\hline Esmeraldas & $\mathrm{O}$ & & & & $\mathrm{O}$ & $x$ \\
\hline Calvas & & & $\mathrm{O}$ & & $\mathrm{O}$ & $x$ \\
\hline Saraguro & & & $\mathrm{O}$ & & $\mathrm{O}$ & $x$ \\
\hline
\end{tabular}

Nota. $\mathrm{O}=$ Contiene parte de un área de conservación; $\mathrm{X}=$ Se encuentran dentro.

\section{Promoción y comercialización}

Según la información registrada en la Tabla 6, los pueblos mágicos utilizan cuatro diferentes plataformas digitales: Facebook (36\%), YouTube (31\%), Instagram (15\%) y sitios web (18\%) (ver Anexo 3). Sin embargo, no todos manejan las cuatro plataformas digitales, siendo así que, 7 de cada 21 manejan hasta dos plataformas, 4 de cada 21 manejan tres, y únicamente tres manejan la totalidad de las plataformas anteriormente descritas. Por otro lado, 17 de cada 21 poseen una página oficial en Facebook, 14 de cada 21 cuentan con un canal en YouTube, 8 de cada 21 poseen una página web propia y 7 de cada 21 manejan una cuenta oficial en Instagram. 
Pero, la forma de gestión difiere en cada plataforma, puesto que la actualización de contenido varía dependiendo del manejo de cada sitio, es así que en Facebook el 75\% de páginas está actualizadas, en páginas web el 33\%, en YouTube el 36\% de los canales se encuentran activos y el 14\% mantiene una actividad regular; mientras que en Instagram el $43 \%$ de las cuentas son activas.

Tabla 6

Promoción en plataformas digitales

\begin{tabular}{|c|c|c|c|c|c|c|c|c|}
\hline \multirow{2}{*}{ Pueblo mágico } & \multicolumn{2}{|c|}{ Facebook } & \multicolumn{2}{|c|}{ Instagram } & \multicolumn{2}{|c|}{ YouTube } & \multicolumn{2}{|r|}{ Sitio web } \\
\hline & $\begin{array}{c}\text { Sitio } \\
\text { oficial }\end{array}$ & Información & $\begin{array}{l}\text { Sitio } \\
\text { oficial }\end{array}$ & Actividad & $\begin{array}{l}\text { Sitio } \\
\text { oficial }\end{array}$ & Actividad & $\begin{array}{l}\text { Sitio } \\
\text { oficial }\end{array}$ & Información \\
\hline Patate & Sí & Desactualizado & Sí & Activo & Sí & Inactivo & Sí & Desactualizado \\
\hline Alausí & Sí & Actualizado & Sí & Activo & Sí & $\begin{array}{l}\text { Medianamente } \\
\text { activo }\end{array}$ & Sí & Actualizado \\
\hline Cotacachi & No & - & No & - & Sí & Inactivo & Sí & Desactualizado \\
\hline Zaruma & No & - & Sí & Activo & Sí & Inactivo & No & - \\
\hline San Gabriel & Sí & Actualizado & No & - & No & - & No & - \\
\hline Guano & Sí & Desactualizado & No & - & No & - & Sí & Actualizado \\
\hline San Antonio de Ibarra & Sí & Actualizado & No & - & Sí & $\begin{array}{l}\text { Medianamente } \\
\text { activo }\end{array}$ & No & - \\
\hline Portoviejo & Sí & Desactualizado & Sí & Inactivo & Sí & Activo & Sí & Desactualizado \\
\hline Rumiñahui & Sí & Actualizado & Sí & Inactivo & Sí & Activo & No & - \\
\hline Azogues & Sí & Actualizado & Sí & Inactivo & No & - & No & - \\
\hline Chordeleg & No & & No & - & Sí & Inactivo & No & - \\
\hline Agua Blanca & Sí & Desactualizado & Sí & Inactivo & No & - & Sí & Desactualizado \\
\hline Shushufindi & Sí & Actualizado & No & - & No & - & No & - \\
\hline Lago Agrio & Sí & Actualizado & No & - & No & - & No & - \\
\hline Pimampiro & No & & No & - & Sí & Inactivo & No & - \\
\hline Isla Floreana & Sí & Actualizado & No & - & No & - & No & - \\
\hline Cayambe & Sí & Actualizado & No & - & Sí & Activo & Sí & Desactualizado \\
\hline El Chaco & Sí & Actualizado & No & - & Sí & Activo & No & - \\
\hline Esmeraldas & No & - & No & - & Sí & Inactivo & No & - \\
\hline Calvas & Sí & Actualizado & No & - & Sí & Activo & No & - \\
\hline Saraguro & Sí & Actualizado & No & - & Sí & Inactivo & Sí & Desactualizado \\
\hline
\end{tabular}


En Facebook existen tres páginas que reciben promoción en mayor o menor medida que los diferentes pueblos mágicos: Ministerio de Turismo Ecuador (58\%), Viaja Ecuador (79\%) y Pueblos Mágicos Ecuador (42\%); de manera global entre las tres páginas se postea al menos dos veces a cada pueblo mágico. Los más promocionados son Saraguro y Cayambe, con un total de cinco publicaciones cada uno, seguidos por Zaruma y Cotacachi con un total de cuatro respectivamente.

Para YouTube, el manejo de la promoción se reduce a dos canales: Ministerio de Turismo, que promociona a 5 de cada 21 pueblos y Ecuador con 3 de cada 21 pueblos, entre ambos únicamente cubren el 24\% del total, es decir 5 pueblos mágicos. Patate, Cotacachi y San Gabriel son las localidades más promocionadas con dos videos cada uno; lo mismo sucede con el sitio web Ecuador, que dentro de su apartado Pueblos Mágicos solamente menciona a los cinco primeros pueblos mágicos creados.

Finalmente, los resultados en la Tabla 7 indican el manejo de la promoción realizada por el MINTUR a los pueblos mágicos. Por medio de Facebook: 82\%, YouTube: 11\% y sitio web: 7\%; sin embargo, no todos reciben de forma equitativa la promoción en estas plataformas, siendo así que, 16 de cada 21 solo son promocionados en Facebook, mientras tanto que, la promoción para Patate, Alausí, Cotacachi, Zaruma y San Gabriel se efectúa en todas las plataformas que maneja el MINTUR.

\section{Conclusiones}

La oferta turística dentro de las localidades que ostentan el reconocimiento de pueblo mágico está dada por tres dimensiones: la primera es la configuración territorial, puesto que la ubicación geográfica influye en la vocación turística y esto se relaciona con la generación de flujos turísticos. La segunda dimensión, es la jerarquía de los atractivos turísticos, que se concibe por la presencia mayoritaria de las manifestaciones culturales sobre los atractivos naturales, superando en 3 a 1 su concentración, y finalmente, la dimensión en la disposición de la prestación de servicios básicos y turísticos, en dónde se destaca que 6 de cada 10 prestadores de servicios pertenecen al sector de alimentos y bebidas sobre los servicios restantes, dando a notar que la cercanía hacia las zonas urbanas, ocasionan que las localidades receptoras se conviertan en lugares de proximidad sin mayor impacto en la pernoctación. No todos los pueblos mágicos tienen un mismo desarrollo y se visualiza claramente con los resultados, ya que seis localidades superan más de 100 registros turísticos, mientras que, cinco locaciones no superan los 10 prestadores de servicios.

El programa Pueblos Mágicos Ecuador es un modelo de gestión que impulsa a la actividad turística, rescatando la identidad local y la revalorización del patrimonio. Depende directamente del compromiso de los actores vinculados al programa establecer estrategias promocionales. Los reconocimientos más representativos en las localidades son la Denominación de origen (52.38\%), Patrimonio Cultural Inmaterial del Ecuador (42.85\%) y Safe Travel (38.09\%). Si bien existen otras denominaciones, es necesario que se aproveche la promoción de los atributos turísticos. Es lamentable que apenas 3 de los 21 pueblos mágicos tengan creados sus canales de promoción digital (redes sociales). 
ANÁLISIS DE LA OFERTA TURÍSTICA DEL PROGRAMA PUEBLOS MÁGICOS ECUADOR - 4 MUNDOS |139

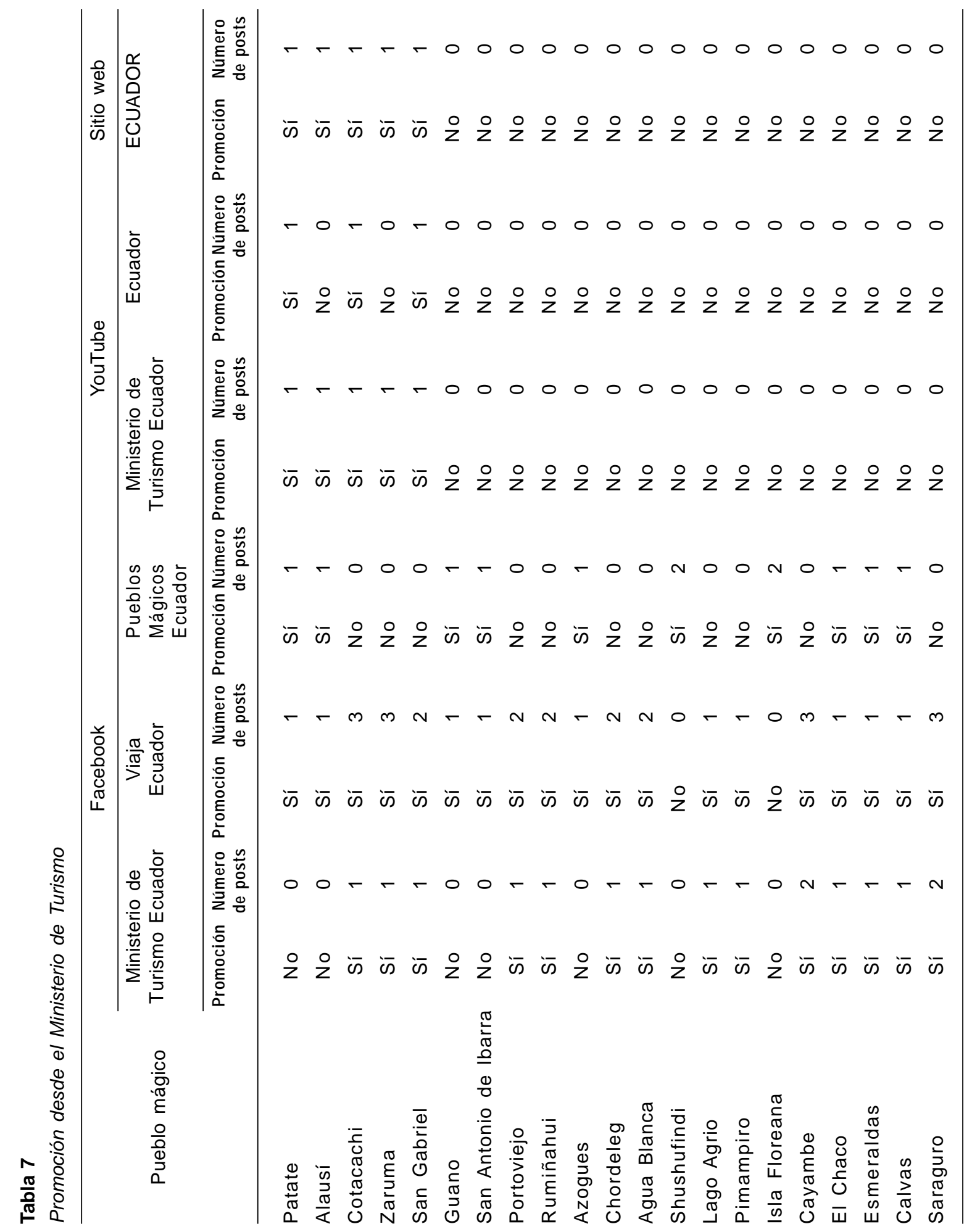


Pueblos Mágicos Ecuador tiene apenas tres años de vigencia y un año y medio de haber declarado su primera localidad: el cantón Patate. Debido a la crisis, generada por la pandemia de la COVID-19, en el primer trimestre del año 2020 la oferta turística no pudo ser aprovechada con relación al objetivo primordial del programa que busca el desarrollo turístico del destino; a lo que se suma las deficientes estrategias promocionales nacionales. Con el avance de la vacunación masiva en el Ecuador, se espera el aumento de los flujos turísticos y el beneficio esperado por las localidades que optaron por ser un pueblo mágico.

\section{Conflicto de intereses}

Los autores no tienen conflicto de intereses con el contenido de este trabajo.

\section{Contribución de autoría}

ERMV: Diseño, elaboración y revisión final del manuscrito[

PAVO: Análisis estadístico y cartográfico $\square$

FRGC: Recolección de datos』

CAVC: Recolección de datos.

\section{Referencias}

Alcívar, I. (2018). El Programa «Pueblos Mágicos» se replicará en Ecuador. Entorno Turístico. Hablemos de turismo. https:// www.entornoturistico.com/el-programa-pueblos-magicos-se-replicara-en-ecuador/

Asociación de Municipalidades Ecuatorianas. (2016). Regúlense las facultades y obligaciones de los gobiernos autónomos descentralizados municipales, metropolitanos, provinciales y parroquiales rurales, respecto al desarrollo de actividades turísticas (Resolución Nº01- CNC- 2016). https://amevirtual.gob.ec/resolucion-0001-cnc-2016/

Barchello, S. O. (2020). Ciudades creativas y su aporte a la creación de un nuevo modelo de desarrollo económico, social y cultural. Una revisión de la literatura. Población y Desarrollo, 50, 53-63. https://dialnet.unirioja.es/servlet/articulo? codigo=742 8620

BirdLife International. (2021). Perfil de país: Ecuador. http://www.birdlife.org/datazone/country/ecuador

Código Orgánico de Organización Territorial, Autonomía y Descentralización. (2010). https://www.cpccs.gob.ec/wp-content/uploads/ 2020/01/cootad.pdf

Conservation International. (2020). Puntos Críticos de Biodiversidad. https://www.conservation.org/priorities/biodiversity-hotspots

Córdoba, M. y Vivanco, L. (2021). El sistema de planificación cantonal del Ecuador: la necesidad de su reforma. Íconos. Revista de Ciencias Sociales, 69, 163-179.

Guerrero, P., Rubio, M., Velasco, D., Lutuala, C., Anguieta, G., Acosta, S., Chalá, J., Juncosa, J., Rosero, F., López, G., Rohn, I., Zambonino, V., Guevara, M. G., Carbonell, E., Ojeda, M., Peñafiel, R., Rodríguez, V., Ubilla, J., Simbaña, F., ... Pico, I. (2020). Patrimonio Inmaterial en el Ecuador. Una construcción colectiva. Universidad Politécnica Salesiana. http://dspace.ups.edu.ec/ handle/12345678 $9 / 18739$

International Whaling Commission. (2021). Descripción general. https://iwc.int/home

Ley Orgánica de Turismo del Ecuador. (2002). https://www.turismo.gob.ec/wp-content/uploads/2015/04/LEY-DE-TURISMO.pdf 
Maguiña, C., Gastelo, R. y Tequen, A. (2020). El nuevo Coronavirus y la pandemia del Covid-19. Revista Médica Herediana, 31(2), 125-131. http://dx.doi.org/10.20453/rmh.v31i2.3776

Ministerio de Cultura y Patrimonio. (2021). Patrimonio Cultural. https://www.culturaypatrimonio.gob.ec/patrimonio-cultural/

Ministerio de Turismo del Ecuador - MINTUR. (2017). Guía metodológica para la jerarquización de atractivos y generación de espacios turísticos del Ecuador. https://servicios.turismo.gob.ec/descargas/

Ministerio de Turismo del Ecuador - MINTUR. (2020a). Transparencia de conocimientos entre Sectur y Mintur busca consolidar el programa Pueblos Mágicos. https://www.turismo.gob.ec/transferencia-de-conocimientos-entre-sectur-y-mintur-busca-consolidarel-programa-pueblos-magicos/

Ministerio de Turismo del Ecuador - MINTUR. (2020b). Bases para la Convocatoria al Programa Pueblos Mágicos Ecuador. https://servicios.turismo.gob.ec/descargas/

Ministerio del Ambiente del Ecuador - MINTUR. (2019). Sitios Ramsar. Criterios para la identificación de humedales de importancia internacional. http://areasprotegidas.ambiente.gob.ec/es/content/sitios-ramsar

Molina, C. A. (2021, 13 de julio). Globalización y desarrollo. El Comercio. https://www.elcomercio.com/cartas/lectores-elcomercioglobalizacion-desarrollo.html

Molina, E., Almeida, D., Carvajal, B., Ormaza, B. y Pozo, D. (2021). Evaluación de los factores geográficos que inciden en los flujos turísticos de la parroquia rural de Guangopolo (Ecuador). Universidad Central del Ecuador. http://www.dspace.uce.edu.ec/handle/ 25000/23916

Parque Nacional Galápagos. (2018). Galápagos cumple 40 años como Patrimonio Natural de la Humanidad. https:// www.galapagos.gob.ec/galapagos-cumple-40-anos-como-patrimonio-natural-de-la-humanidad/

Pazos, C. (2001). Documento pedagógico; Patrimonio turístico nacional I Geografía. Universidad de Especialidades Turísticas.

Pinchevsky, M. (2021). Ecuador ya suma 21 pueblos mágicos para el turismo. El Universo. https://www.eluniverso.com/larevista/ turismo/ecuador-ya-suma-21-pueblos-magicos-para-el-turismo-nota/

Pineda, A., Sojos, G. y Calle, M. (2019). Análisis del sistema turístico de la parroquia Casacay, Pasaje, Ecuador. Revista interamericana de ambiente y turismo, 15(2), 162-169.

Sánchez, S. (2018). El papel de las denominaciones de origen en el turismo sostenible. Ostelea. Tourism Management School. https:// www.ostelea.com/actualidad/noticias/el-papel-de-las-denominaciones-de-origen-en-el-turismo-sostenible

Secretaría de Turismo de México - SECTUR. (2017). Ficha Técnica de Evaluación. https://www.gob.mx/cms/uploads/

Secretaría de Turismo de México - SECTUR. (2020). Estrategia Nacional de Pueblos Mágicos. http://sistemas.sectur.gob.mx/ PueblosMagicos/Formatos/

Seiscientos treinta hoteles del Ecuador permanecen cerrados; algunos administradores analizan la suspensión definitiva. (2020, 13 de julio). El Comercio. https://www.elcomercio.com/actualidad/hoteles-ecuador-cerrados-pandemia-coronavirus.html

Sistema Nacional de Áreas de Conservación Costa Rica. (2021). Reservas de la Biósfera. http://www.sinac.go.cr/ES/RESERBIOSFE/ Paginas/default.aspx

Sistema Nacional de Áreas Protegidas del Ecuador. (2021). ¿Qué es el Sistema Nacional de Áreas Protegidas? http:// areasprotegidas.ambiente.gob.ec/es/info-snap

Servicio Nacional de Derechos Intelectuales. (2021). Denominación de Origen. https://www.derechosintelectuales.gob.ec/denominacionde-origen/

World Travel and Tourism Council. (2021). Viajes Seguros: Protocolos globales y selo para la nueva normalidad. https://wttc.org/ COVID-19/Safe-Travels-Global-Protocols-Stamp 
Edison Rubén Molina Velásquez

Universidad Central del Ecuador, Ecuador.

Doctor en Geografía Universidad Nacional del Sur (Argentina). Docente titular Agregado 3, Universidad Central del Ecuador, Facultad de Ciencias Agrícolas, Facultad de Ciencias Agrícolas, carreras de Turismo Ecológico y Turismo Rediseño. Líneas de investigación: Turismo Alternativo, Patrimonio Turístico; Estudios Administrativos y Económicos del Turismo; Espacios de Ocio.

ermolina@uce.edu.ec / edisonmolina10@gmail.com

ORCID: https://orcid.org/0000-0001-7702-5079

Pedro Andrés Villagrán Olivo

Universidad Central del Ecuador, Ecuador.

Licenciado en Turismo Ecológico, Universidad Central del Ecuador. Estudiante de posgrado, Universidad de Buenos Aires (Argentina). Líneas de investigación: Sistemas de información geográfica aplicado al turismo, Mapeo temático, Economía y Gestión turística, Planificación turística.

85VI1724813975@campus.economicas.uba.ar / andresp1792@gmail.com

ORCID: https://orcid.org/0000-0002-8374-1829

Franklin Raúl Guerrero Carvajal

Universidad Central del Ecuador, Ecuador.

Licenciatura en Turismo Ecológico, Universidad Central del Ecuador. Estudiante egresado de la Universidad Central del Ecuador, Ecuador. Líneas de investigación: Gobernanza Turística, Turismo Alternativo, Promoción Turística.

frguerrero@uce.edu.ec / ralrg50@gmail.com

ORCID: https://orcid.org/0000-0002-5273-5389

Cristina Alejandra Villarreal Cando

Universidad Central del Ecuador, Ecuador.

Licenciatura en Turismo Ecológico Universidad Central del Ecuador. Estudiante Egresada de la Universidad Central del Ecuador. Líneas de investigación: Empresas turísticas, Estudio de Percepción en Satisfacción y Servicios Prestados.

cavillarreal@uce.edu.ec / crisvilla1496@hotmail.com

ORCID: https://orcid.org/0000-0002-3354-7323 


\section{Anexo 1}

\section{Certificaciones y denominaciones}

\begin{tabular}{cl}
\hline Nombre & \multicolumn{1}{c}{ Descripción } \\
\hline & Sello de calidad de viaje diseñado por el Consejo Mundial de Viajes y Turismo. \\
Este sello está diseñado por Consejo Mundial de Viajes y Turismo el cual ayuda \\
Safe Travel & a que los turistas tengan conocimiento de empresas o destinos que \\
& implementen protocolos de salud e higiene, los cuales se basan en información \\
& actualizada de la Organización Mundial de la Salud (OMS) (World Travel and \\
& Tourism Conuncil, 2021).
\end{tabular}

\section{Ciudades creativas}

Patrimonio Cultural Inmaterial del Ecuador

\section{Patrimonio de la} Humanidad

\section{Denominación de Origen}

Áreas Protegidas

Reserva de la Biosfera
Se creó en 2004, y su objetivo es cubrir siete ámbitos como artesanías o artes populares, artes digitales, cine, diseño, gastronomía, literatura y música (Barchello, 2020).

El patrimonio cultural se compone de todo aquello que a lo largo de la historia han sido producidas por los habitantes de un territorio, como conocimientos, manifestaciones, saberes y prácticas culturales, que promuevan un sentimiento de identidad, motivando la valoración de lo propio. Está vigente en el país desde el año 2008 (Guerrero et al., 2020).

Desde 1972 la Organización de las Naciones Unidas para la Educación, la Ciencia y la Cultura (UNESCO) establece la protección de ciertos lugares de la tierra que tengan un «valor excepcional universal». En el caso cultural el patrimonio será un conjunto de bienes y prácticas sociales, creadas, mantenidas, transmitidas y reconocidas por las personas, comunidades, pueblos y nacionalidades. (Ministerio de Cultura y Patrimonio, 2021; Parque Nacional Galápagos, 2018).

Es un tipo de distintivo posee similitudes a una marca, dentro del Ecuador estas denominaciones son aquellas que identifican una región o un lugar determinado y coexisten con factores naturales y humanos que intervienen en sus procesos de producción y extracción; los objetivos de estas denominaciones generan desarrollo local al poseer un valor agregado, logrando un mejor precio en el mercado. Su difusión y concesión es encargada a las Direcciones Nacionales de Propiedad Industrial y Obtenciones Vegetales (Servicio Nacional de Derechos Intelectuales, 2021)

Estos sitios son manejados por el Sistema Nacional de Áreas Protegidas del Ecuador y están destinados a garantizar la conservación de la biodiversidad y el mantenimiento de las funciones ecológicas, existen ocho categorías de manejo: parques nacionales, reserva marina, reservas ecológicas, reserva biológica, reserva de producción de flora y fauna, refugio de vida silvestre, área natural de recreación y reserva geobotánica (Sistema Nacional de Áreas Protegidas del Ecuador, 2021).

Desde 1974 la Organización de las Naciones Unidas para la Educación, la Ciencia y la Cultura (UNESCO) crea esta denominación con el objetivo de gestionar una apropiada sustentabilidad y convivencia entre los seres humanos y la naturaleza, permitiendo con esto la conservación de ecosistemas completos en todo el planeta (Sistema Nacional de Áreas de Conservación Costa Rica, 2021). 


\begin{tabular}{|c|c|}
\hline Nombre & Descripción \\
\hline Santuario de Ballenas & $\begin{array}{l}\text { Desde el } 2007 \text { Ecuador pertenece a la Comisión Ballenera Internacional (CBI) } \\
\text { el cual tiene como objetivo principal el cual vela por la conservación adecuada } \\
\text { de cetáceos, designando áreas específicas como santuarios, entre otras } \\
\text { actividades que regularán el desarrollo de la industria ballenera (International } \\
\text { Whaling Commission, 2021). }\end{array}$ \\
\hline Sitios Ramsar & $\begin{array}{l}\text { Son aquellos que conservan y usan de manera racional los recursos naturales } \\
\text { a través del cuidado de los humedales cuyas funciones son regulador } \\
\text { hidrológico y hábitat de biodiversidad tanto de flora como de fauna. El territorio } \\
\text { ecuatoriano forma parte de este tratado de conservación desde } 1991 \text { (Ministerio } \\
\text { del Ambiente del Ecuador, 2019). }\end{array}$ \\
\hline $\begin{array}{l}\text { Áreas Importantes } \\
\text { para las aves y la } \\
\text { biodiversidad (IBA) }\end{array}$ & $\begin{array}{l}\text { Estos sitios son identificados mediante criterios establecidos por expertos } \\
\text { siendo su objetivo la protección y custodia de poblaciones de aves, convirtiendo } \\
\text { a estos lugares en sitios estratégicos para la supervivencia de muchas especies } \\
\text { animales y vegetales. Existen más de } 12000 \text { IBA's en el mundo, en Ecuador } \\
\text { se encuentran } 109 \text { sitios registrados (BirdLife International, 2021). }\end{array}$ \\
\hline Hotspots & $\begin{array}{l}\text { Estos sitios se denominan así por el alto grado de concentración de especies } \\
\text { endémicas las cuales enfrentan altos grados de amenaza. Ecuador pose } 3 \text { de } \\
\text { los } 34 \text { hotspots del mundo (Conservation International, 2020). }\end{array}$ \\
\hline
\end{tabular}


Anexo 2

Inventario de los 75 atractivos turísticos registrados

\begin{tabular}{|c|c|c|c|}
\hline $\mathrm{n} .^{\circ}$ & Provincia & Cantón & Nombre del atractivo \\
\hline 1 & Imbabura & Cotacachi & Laguna de Cuicocha \\
\hline 2 & Carchi & Montúfar & Cascada de Paluz \\
\hline 3 & Chimborazo & Alausí & Nariz del diablo - Estación de Sibambe \\
\hline 4 & Carchi & Montúfar & Gruta de la Paz \\
\hline 5 & Pichincha & Cayambe & Reloj solar Quitsato \\
\hline 6 & Chimborazo & Guano & Museo de la ciudad \\
\hline 7 & Esmeraldas & Esmeraldas & Museo y centro cultural Esmeraldas \\
\hline 8 & Esmeraldas & Esmeraldas & Museo Arqueológico Carlos Mercado Ortiz \\
\hline 9 & Esmeraldas & Esmeraldas & Monumento a los marimberos \\
\hline 10 & Esmeraldas & Esmeraldas & Encocao en playa Las Palmas \\
\hline 11 & Esmeraldas & Esmeraldas & Playa Las Palmas \\
\hline 12 & Esmeraldas & Esmeraldas & Puerto pesquero artesanal de Esmeraldas \\
\hline 13 & Esmeraldas & Esmeraldas & Marimba en conservatorio municipal \\
\hline 14 & Esmeraldas & Esmeraldas & Malecón playa Las Palmas \\
\hline 15 & Pichincha & Rumiñahui & Fiesta del maíz y turismo \\
\hline 16 & Pichincha & Rumiñahui & Mausoleo Juan de Salinas \\
\hline 17 & Pichincha & Rumiñahui & Mercado el turismo \\
\hline 18 & Pichincha & Rumiñahui & Monumento Aya Huma \\
\hline 19 & Pichincha & Rumiñahui & Parque El Ejido \\
\hline 20 & Pichincha & Rumiñahui & Parque el turismo \\
\hline 21 & Pichincha & Rumiñahui & Toros populares \\
\hline 22 & Pichincha & Rumiñahui & Centro cultural Villa Carmen \\
\hline 23 & Imbabura & Cotacachi & Artesanías en cuero \\
\hline 24 & Imbabura & Ibarra & Artesanías talladas en madera \\
\hline 25 & Imbabura & Ibarra & Centro cultural Daniel Reyes \\
\hline 26 & Imbabura & Ibarra & Helados de paila de Ibarra \\
\hline 27 & Imbabura & Cotacachi & Museo de las culturas \\
\hline 28 & Imbabura & Ibarra & Monumento el Arcángel San Miguel \\
\hline 29 & Imbabura & Ibarra & Museo de Ibarra \\
\hline 30 & El Oro & Zaruma & Café Zaruma \\
\hline 31 & El Oro & Zaruma & Fiesta de semana santa en el cerro El Calvario \\
\hline 32 & El Oro & Zaruma & Sitio arqueológico cerro Chivaturco \\
\hline 33 & El Oro & Zaruma & Fiestas de la Virgen del Carmen \\
\hline 34 & El Oro & Zaruma & Iglesia de Abañin \\
\hline 35 & El Oro & Zaruma & Iglesia de Arcapamba \\
\hline 36 & El Oro & Zaruma & Iglesia de Güizhagüiña \\
\hline 37 & El Oro & Zaruma & Iglesia Huertas \\
\hline
\end{tabular}




\begin{tabular}{|c|c|c|c|}
\hline n. ${ }^{\circ}$ & Provincia & Cantón & Nombre del atractivo \\
\hline 38 & El Oro & Zaruma & Iglesia de Malvas \\
\hline 39 & El Oro & Zaruma & Iglesia de Muluncay \\
\hline 40 & El Oro & Zaruma & Iglesia de Salvias \\
\hline 41 & El Oro & Zaruma & Iglesia de Sinsao \\
\hline 42 & El Oro & Zaruma & Mina el Sexmo \\
\hline 43 & El Oro & Zaruma & Museo municipal de Zaruma \\
\hline 44 & El Oro & Zaruma & El tigrillo \\
\hline 45 & Azuay & Chordeleg & Artesanías en paja toquilla Chordeleg \\
\hline 46 & Azuay & Chordeleg & Orfebrería en Chordeleg \\
\hline 47 & Pichincha & Rumiñahui & Bosque Cedrillos \\
\hline 48 & Pichincha & Rumiñahui & Cascada Cóndor Machay \\
\hline 49 & Pichincha & Rumiñahui & Cascada Kimsa \\
\hline 50 & Pichincha & Rumiñahui & Cascada Las Gemelas \\
\hline 51 & Pichincha & Rumiñahui & Cascada Nido de Curiquingue \\
\hline 52 & Pichincha & Rumiñahui & Cascada Sueño de Novia \\
\hline 53 & Pichincha & Rumiñahui & Centro comercial River Mall \\
\hline 54 & Pichincha & Rumiñahui & Cuevas del arcoiris \\
\hline 55 & Pichincha & Rumiñahui & Hornado - Sangolquí \\
\hline 56 & Pichincha & Rumiñahui & Iglesia San Juan Bautista de Sangolquí \\
\hline 57 & Pichincha & Rumiñahui & Monumento al Colibrí \\
\hline 58 & Pichincha & Rumiñahui & Parque Alegria \\
\hline 59 & Pichincha & Rumiñahui & Pileta luminosa (Santa María) \\
\hline 60 & Pichincha & Rumiñahui & Plaza central de Sangolquí \\
\hline 61 & Pichincha & Rumiñahui & Quinta Bolivia \\
\hline 62 & Pichincha & Rumiñahui & Vertiente los saucos \\
\hline 63 & Pichincha & Rumiñahui & Iglesia señor de los dos puentes \\
\hline 64 & Pichincha & Rumiñahui & Parque Eduardo Kingman \\
\hline 65 & Manabí & Portoviejo & Balneario de agua dulce Vista Hermosa \\
\hline 66 & Manabí & Portoviejo & Iglesia la catedral Jesús del Buen Pastor \\
\hline 67 & Manabí & Portoviejo & Jardín botánico Universidad Técnica de Manabí \\
\hline 68 & Manabí & Portoviejo & Manglar La Boca \\
\hline 69 & Manabí & Portoviejo & Parque La Rotonda \\
\hline 70 & Manabí & Portoviejo & Parque Ecológico El Mamey \\
\hline 71 & Manabí & Portoviejo & Parque Las Vegas \\
\hline 72 & Manabí & Portoviejo & Playa La Boca \\
\hline 73 & Tungurahua & Patate & Santuario Señor del Terremoto \\
\hline 74 & Tungurahua & Patate & Cascada de Mundug \\
\hline 75 & Manabí & Portoviejo & Playa Crucita \\
\hline
\end{tabular}




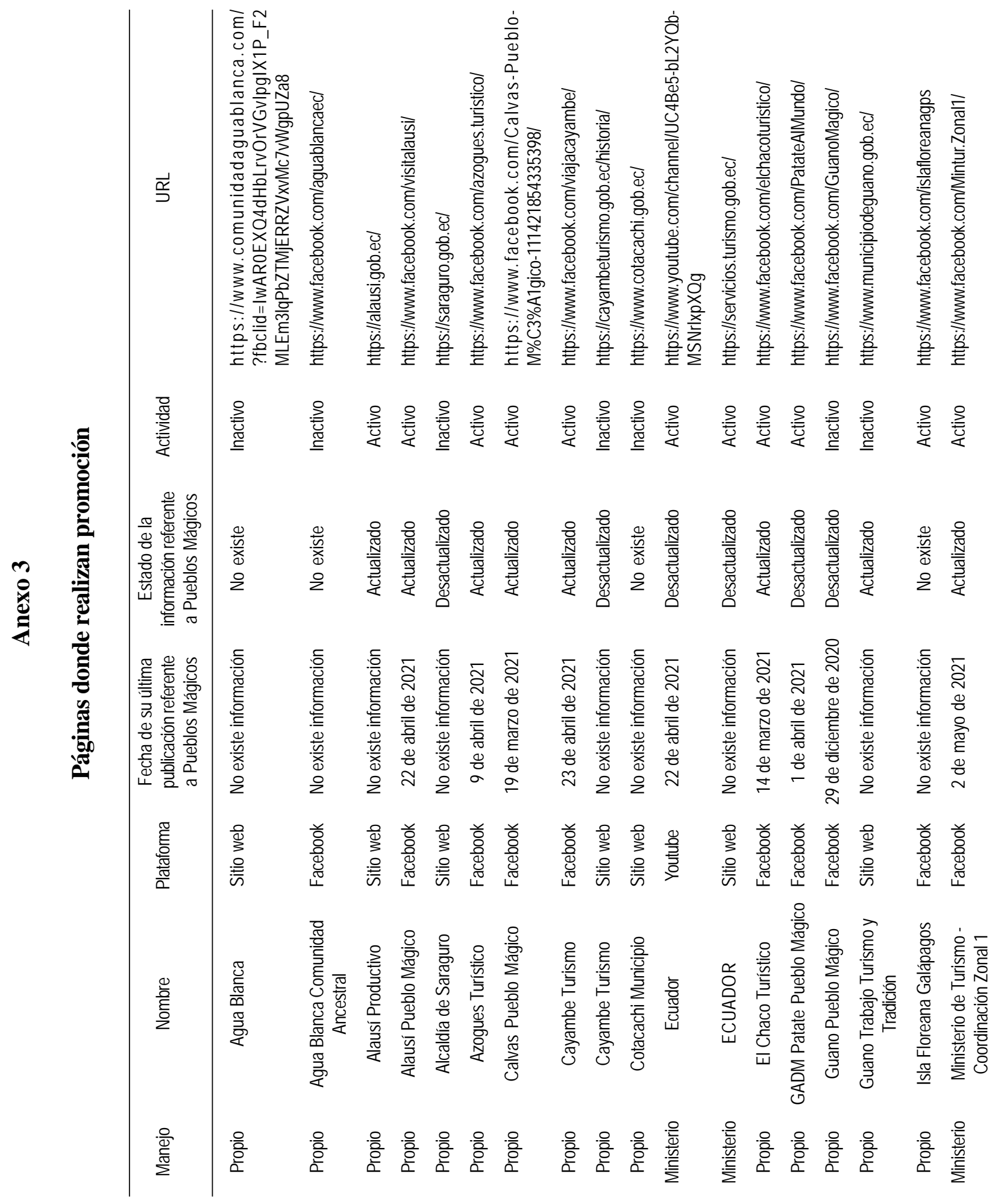




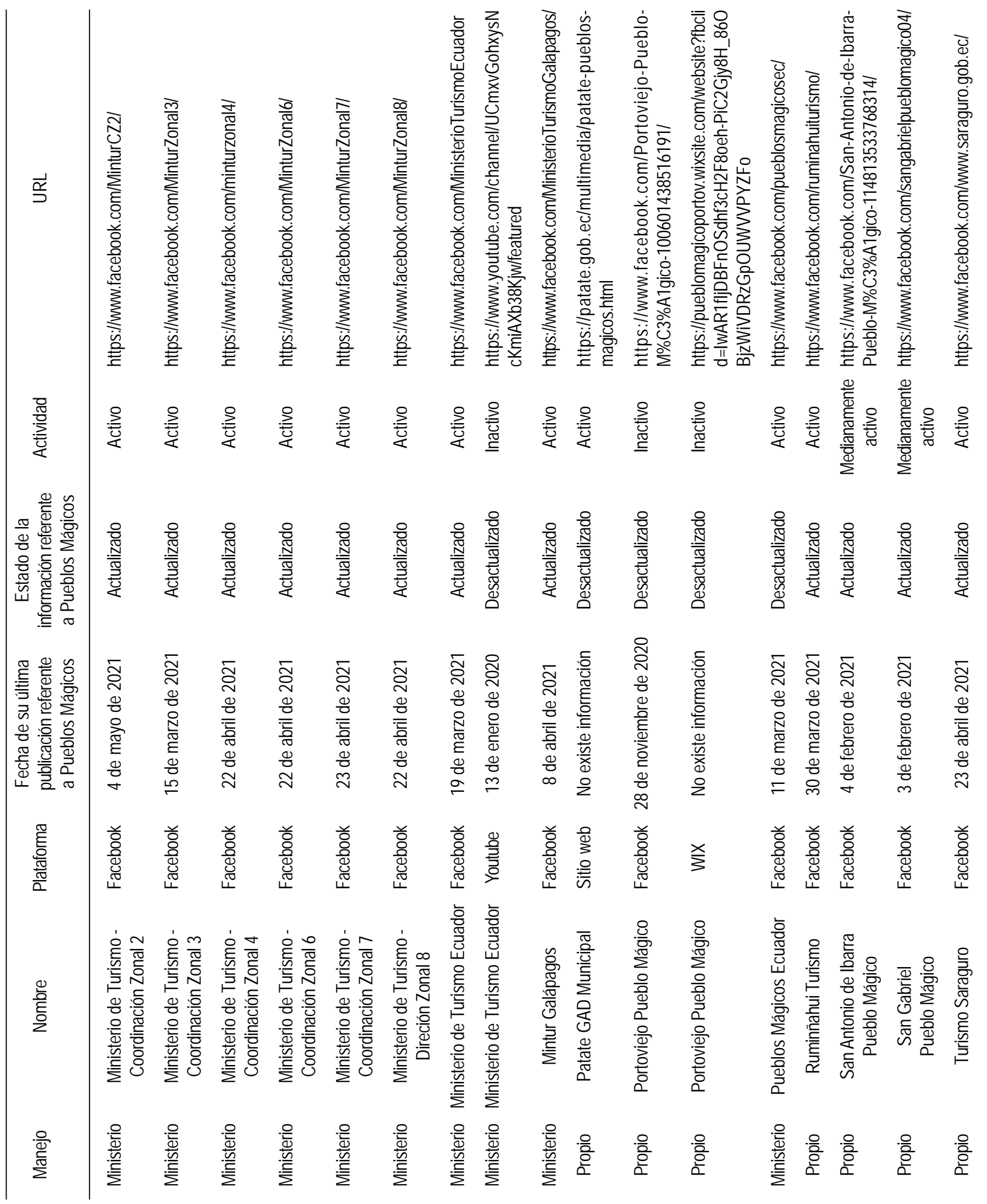




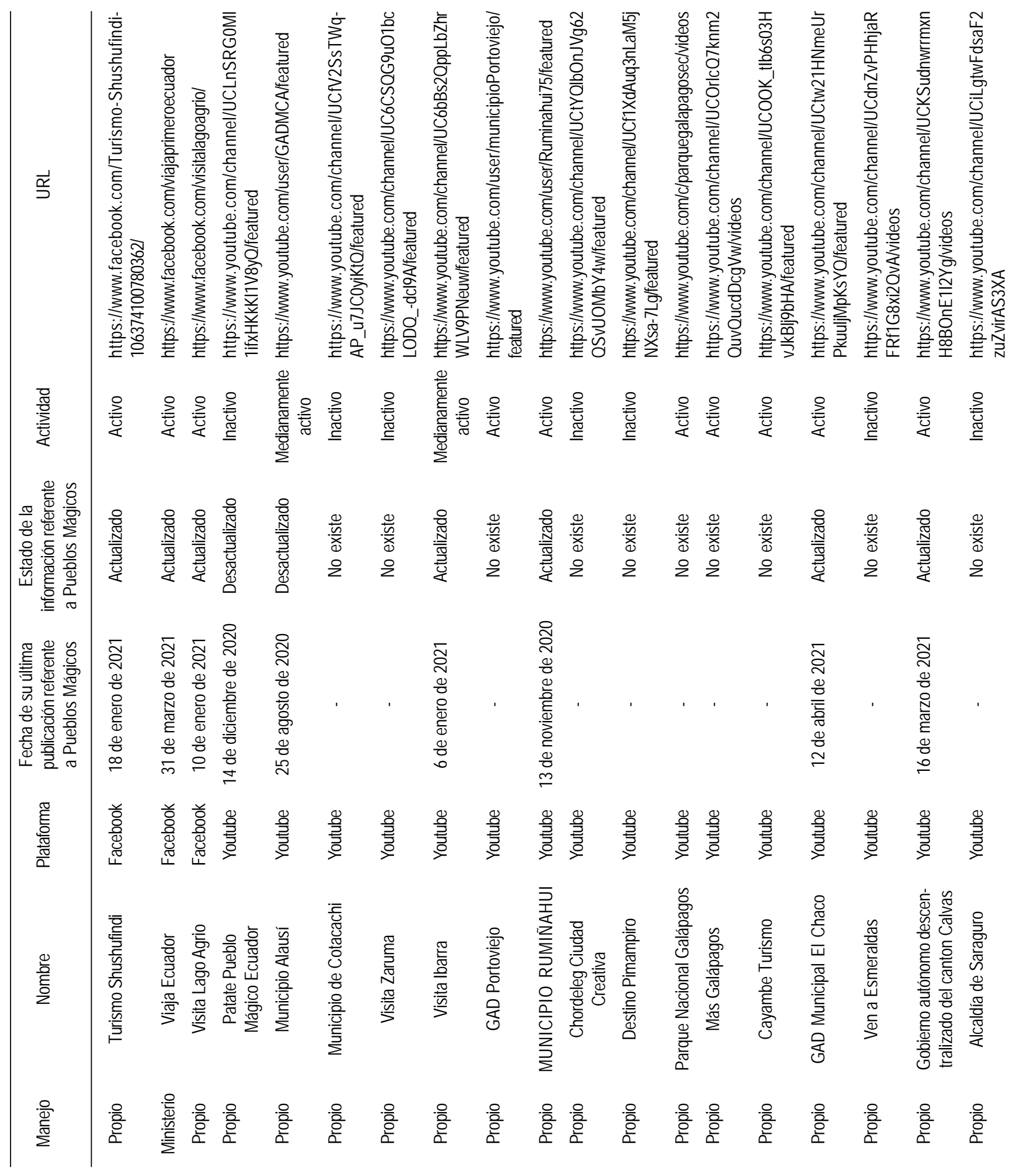

